\title{
Febre Maculosa por Rickettsia parkeri no Brasil: condutas de vigilância epidemiológica, diagnóstico e tratamento
}

\section{Rickettsia parkeri spotted fever in Brazil: Epidemiological surveillance, diagnosis and treatment}

\author{
Álvaro A. Faccini-Martínez ${ }^{1,2}$, Stefan Vilges de Oliveira ${ }^{3,4}$, Crispim Cerutti Junior $^{5}$, Marcelo B. Labruna ${ }^{6}$
}

1. Doutorando do Programa de Pós-Graduação em Doenças Infecciosas do Centro de Ciências da Saúde da Universidade Federal do Espírito Santo (UFES), Vitória, ES, Brasil. 2. Membro do Comité de Medicina Tropical, Zoonosis y Medicina del Viajero, Asociación Colombiana de Infectología, Bogotá, Colombia. 3. Consultor Técnico do Departamento de Vigilância das Doenças Transmissíveis da Secretaria de Vigilância em Saúde do Ministério da Saúde (SVS/MS), Brasília, DF, Brasil. 4. Pesquisador do Laboratório de Referência Nacional para Vetores das Riquetsioses da Fundação Oswaldo Cruz (FIOCRUZ), Rio de Janeiro, RJ, Brasil. 5. Docente do Programa de Pós-Graduação em Doenças Infecciosas do Centro de Ciências da Saúde da Universidade Federal do Espírito Santo (UFES), Vitória, ES, Brasil. 6. Docente do Departamento de Medicina Veterinária Preventiva e Saúde Animal da Faculdade de Medicina Veterinária e Zootecnia da Universidade de São Paulo (USP), SP, Brasil.

\section{Resumo}

Introdução: A febre maculosa (FM) é uma doença infecciosa, aguda, transmitida por carrapatos, e de gravidade variável. No Brasil, recentemente, tem sido descrita uma nova FM causada por Rickettsia parkeri, cujo perfil clínico, epidemiológico e laboratorial é diferente do perfil da FM causada por Rickettsia rickettsii. Metodologia: trata-se de uma revisão narrativa cujo objetivo é caracterizar a febre maculosa causada por Rickettsia parkeri no Brasil, discutindo as condutas de vigilância epidemiológica, diagnóstico e tratamento. Resultados: A febre maculosa por Rickettsia parkeri no Brasil é produzida, principalmente, pela R. parkeri cepa Mata Atlântica, presente no bioma Mata Atlântica das regiões Sul, Sudeste e Nordeste, onde o carrapato Amblyomma ovale figura como o principal vetor da doença. A suspeição clínica e epidemiológica deve considerar os pacientes que apresentam doença febril e presença da escara de inoculação, associadas à visita em área de mata e ou contatos com carrapatos. A coleta de material biológico (que inclua a escara de inoculação) deve ser realizada, oportunamente, para a caracterização do agente etiológico. 0 tratamento com antibioticoterapia deve ser iniciado já no início dos sintomas, e todos os casos devem ser notificados ao Ministério da Saúde e investigados imediatamente. A caracterização do ambiente de infecção é importante para melhor compreensão da ecoepidemiologia da doença e desencadeamento de medidas de prevenção e controle. Conclusão: Estabelecemos um protocolo para os profissionais de saúde com as condutas de vigilância epidemiológica, diagnóstico e tratamento para febre maculosa causada por Rickettsia parkeri no Brasil.

Palavras-chave: Carrapatos. Vetores de Doenças. Epidemiologia. Rickettsia. Saúde Pública.

\begin{abstract}
Introduction: Spotted fever (SF) is a tick-borne infectious disease, acute and of variable gravity. In Brazil, recently a new SF has been described, caused by Rickettsia parkeri, whose clinical, epidemiological and laboratory profile is different from the SF profile caused by Rickettsia rickettsii. Methodology: Here in, we present a narrative review with the objective of characterizing Rickettsia parkeri SF in Brazil, discussing the conduct of epidemiological surveillance, diagnosis and treatment. Results: Rickettsia parkeri SF in Brazil is mainly produced by R. parkeri strain Atlantic Forest, present in the Atlantic Forest biome of the South, Southeast and Northeast regions, where Amblyomma ovale tick is the main vector of the disease. The clinical and epidemiological suspicion should consider the patients with febrile disease with the presence of inoculation eschar, associated to the visit in forest area and or contact with ticks. The collection of biological material (including eschar) should be carried out in a timely manner to characterize the etiological agent. Antibiotic treatment should be started at the onset of symptoms and all cases should be reported to the Ministry of Health and investigated immediately. The characterization of the infection environment is important for a better understanding of the ecoepidemiology of the disease and the triggering of prevention and control measures. Conclusion: We have established a protocol for health professionals with ecoepidemiology surveillance, diagnosis and treatment for Rickettsia parkeri SF in Brazil.
\end{abstract}

Key words: Ticks. Disease Vectors. Epidemiology. Rickettsia. Public Health.

\section{INTRODUÇÃO}

As riquetsioses do grupo da febre maculosa (GFM) são doenças infecciosas de caráter zoonótico, causadas por bactérias patogênicas do gênero Rickettsia, transmitidas ao homem por meio da picada de carrapatos ${ }^{1}$. Nas últimas décadas, essas doenças têm sido reconhecidas como emergentes e reemergentes ao redor do mundo no contexto da etiologia e do diagnóstico diferencial da síndrome febril aguda².

A epidemiologia das riquetsioses encontra-se diretamente relacionada à presença e distribuição geográfica dos carrapatos vetores, das variáveis ecológicas e da abundância de hospedeiros animais envolvidos no ciclo das riquétsias na natureza ${ }^{1,3}$. 
Clinicamente, caracterizam-se por serem doenças febris agudas, associadas, na maioria dos casos, a sinais e sintomas inespecíficos, porém, com algumas manifestações dermatológicas sugestivas (exantema e/ou a escara de inoculação) ${ }^{2,4}$. A evolução da enfermidade pode ser variável, desde quadros clínicos leves até casos graves, com manifestações íctero-hemorrágicas, dependendo de fatores como a patogenicidade da espécie de Rickettsia infectante, tempo do início do tratamento antibiótico e fatores próprios do indivíduo².

No Brasil, Rickettsia rickettsii é a espécie patogênica de maior importância, figurando como o agente etiológico da Febre Maculosa Brasileira (FMB), uma doença febril hemorrágica, de notificação compulsória imediata, endêmica na região Sudeste, com taxas de letalidade acima de $50 \%^{5}$. No entanto, recentemente, tem sido descrita uma nova riquetsiose do GFM no território brasileiro, cujas manifestações clínicas tendem a ser menos graves ao quadro clínico desencadeado por $R$. rickettsii, com presença de febre, escara de inoculação, erupção cutânea e linfadenopatía, sendo Rickettsia parkeri cepa Mata Atlântica o principal agente etiológico ${ }^{6-9}$; porém, é provável que Rickettsia parkeri sensu stricto também participe na etiologia ${ }^{10}$.

Dado o quadro clínico diferenciado, observado na febre maculosa causada por $R$. parkeri, quando comparado com a $\mathrm{FMB}^{11}$, o presente estudo objetiva realizar uma revisão narrativa das publicações neste campo, visando identificá-las e discuti-las. O conhecimento resultante do presente estudo pode viabilizar o embasamento e o aprimoramento das condutas de vigilância epidemiológica, diagnóstico e tratamento para os profissionais da saúde no Brasil.

\section{METODOLOGIA}

Uma revisão da literatura narrativa ${ }^{12}$ reuniu informações sobre as infecções por $R$. parkeri em humanos e em carrapatos, as quais estão associadas a quadros clínicos que apresentam a escara de inoculação no Brasil. Foram abordados: I) a situação epidemiológica no Brasil (cenários de transmissão, distribuição espacial de riquétsias e vetores das riquetsioses, associados à escara de inoculação); II) as condutas e diagnósticos (suspeição clínica, epidemiológica, diagnóstico diferencial, coleta e processamento de amostras); III) o Tratamento (antibioticoterapia recomendada) e IV) a vigilância epidemiológica (notificação, investigação, prevenção e controle).

\section{RESULTADOS E DISCUSSÃO}

\section{Situação epidemiológica da febre maculosa causada por Rickettsia parkeri no Brasil}

A febre maculosa causada por $R$. parkeri ocorre predominantemente em áreas de Mata Atlântica nas regiões Sul, Sudeste e Nordeste ${ }^{7-9}$ (Figura 1), onde a R. parkeri cepa Mata
Atlântica é o agente etiológico, associado, principalmente, ao carrapato Amblyomma ovale como vetor competente ${ }^{13}$.

Figura 1. Distribuição das infeç̧ões por Rickettsia parkeri cepa Mata Atlântica e Rickettsia parkeri sensu stricto em Amblyomma ovale, Amblyomma tigrinum, Amblyomma triste e humanos na América do Sul.

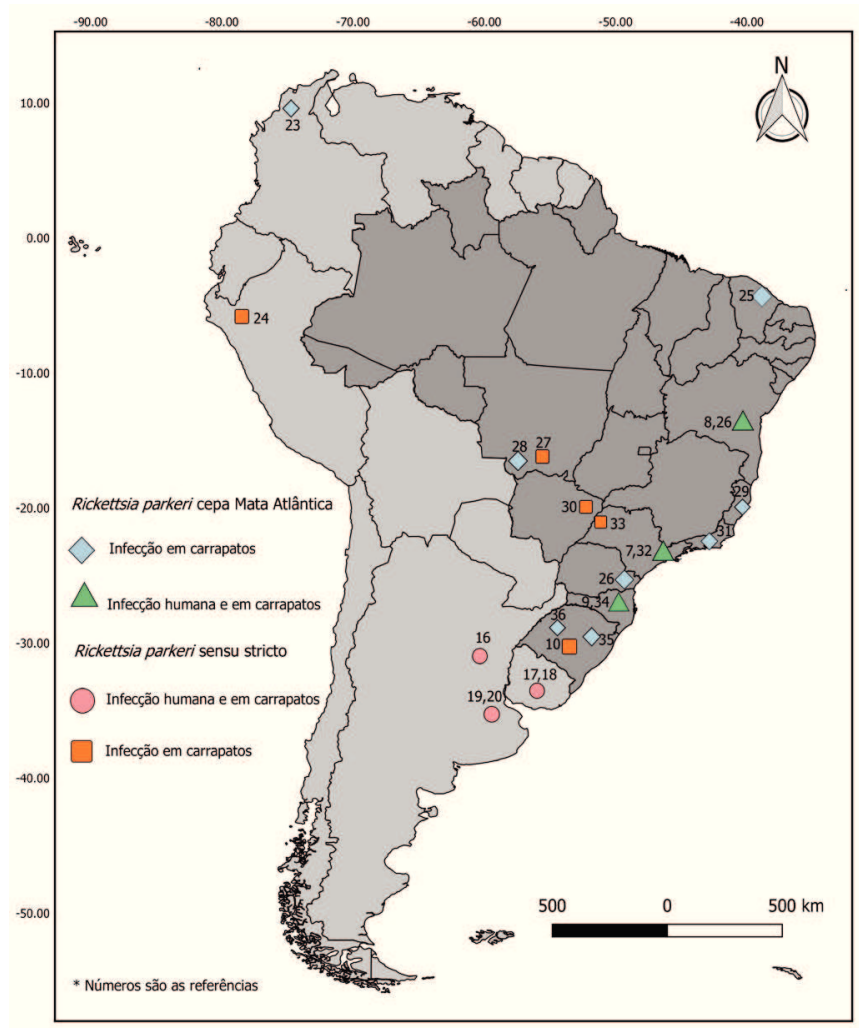

Neste cenário de transmissão, os humanos têm risco de entrar em contato com os estágios adultos de $A$. ovale, seja por atividades diversas em áreas preservadas de Mata Atlântica, seja no domicílio/peridomicílio pela convivência com cães que têm acesso livre a áreas de Mata Atlântica (de onde vêm parasitados com carrapatos) ${ }^{3}$ (Figura 2).

As manifestações clínicas, com presença de febre, escara de inoculação, erupção cutânea e linfadenopatia ${ }^{7-9}$, tendem a ser menos graves ao quadro clínico desencadeado por $R$. rickettsii.

Segundo os poucos casos confirmados ${ }^{7-9}$, além dos dados epidemiológicos dos estados brasileiros onde essa FM parece ser predominante (ex. Rio Grande do Sul ${ }^{14}$, Santa Catarina ${ }^{11}$, litoral de São Paulo e Ceará ${ }^{15}$ ) (Figura 1), a doença não apresenta complicações em sua evolução, e não há indícios de letalidade associada $^{5,14,15}$. Por enquanto, não tem sido definido um padrão de sazonalidade específico.

Como fato interessante, segundo pesquisas recentes ${ }^{10}$, é provável que exista um outro cenário de transmissão de FM causada por R. parkeri, predominante, por enquanto, no bioma Pampa brasileiro (estado do Rio Grande do Sul), onde foram coletados 
carrapatos adultos Amblyomma tigrinum infectados com a espécie patogênica Rickettsia parkeri sensu stricto em áreas rurais com relatos prévios de febre maculosa em humanos ${ }^{10,14}$ Este perfil é semelhante ao padrão epidemiológico sugerido em algumas regiões da Argentina, onde $A$. tigrinum é apontado como o vetor de $R$. parkeri ${ }^{16}$ e também em outros países, onde Amblyomma triste (Uruguai ${ }^{17,18}$ e Argentina ${ }^{19,20}$ ) e Amblyomma maculatum (Estados Unidos) são vetores reconhecidos de $R$. parkeri para humanos ${ }^{21,22}$.

A distribuição das infecções por Rickettsia parkeri cepa Mata Atlântica e Rickettsia parkeri sensu stricto em Amblyomma ovale, Amblyomma tigrinum, Amblyomma triste e humanos na América do Sul é apresentada na Figura $1^{7-10,16-20,23-36}$.

Figura 2. Local provável de infecção de casos humanos da febre maculosa causada por Rickettsia parkeri cepa Mata Atlântica, no município de Blumenau, estado de Santa Catarina. (Fonte: autor, Marcelo B. Labruna).

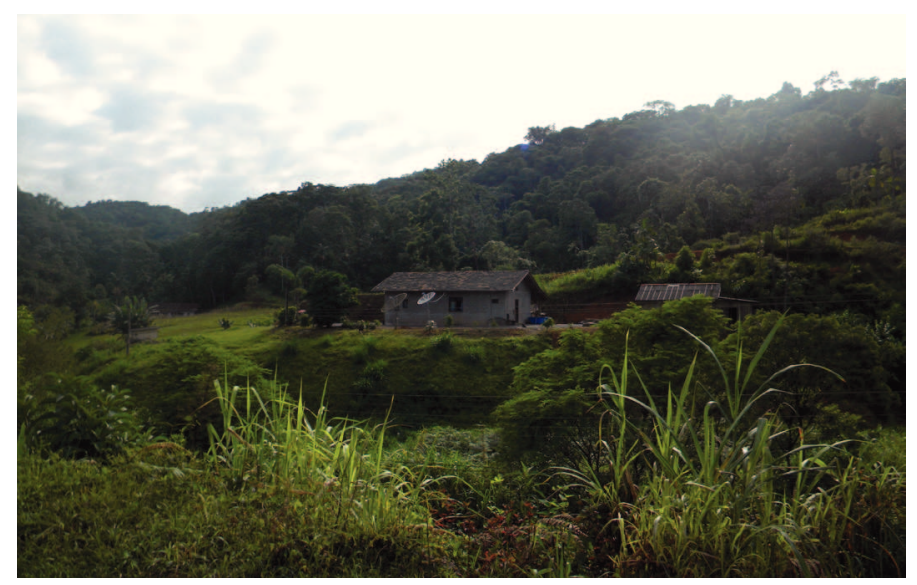

Carrapatos vetores de Rickettsia parkeri no Brasil

Amblyomma ovale

Em condições naturais, $A$. ovale é um carrapato de três hospedeiros; os estágios imaturos (larvas e ninfas) alimentamse, principalmente, em roedores, e os estádios adultos, em espécies de animais da ordem Carnívora (principalmente canídeos e felídeos) $)^{3,37,38}$. É reconhecida como uma das principais espécies do gênero Amblyomma com hábitos antropofílicos (parasitismo em humanos), principalmente os estágios adultos ${ }^{39,40}$.

No Brasil, registra-se a distribuição geográfica desta espécie de carrapato nos seguintes biomas: Pantanal ${ }^{41}$, Amazônia ${ }^{42}$, Cerrado $^{43}$ e Mata Atlantica ${ }^{38}$. Neste último, por enquanto, $A$. ovale tem sido encontrado infectado com Rickettsia parkeri cepa Mata Atlântica com taxas de infecção entre $3 \%$ e $85 \%{ }^{29,44}$. Além disso, estudos experimentais recentes têm mostrado que $A$. ovale é reservatório (transmissão transovariana e perpetuação transestadial) e vetor competente da Rickettsia parkeri cepa
Mata Atlântica, porém a infecção riquetsial produz um efeito deletério nas fêmeas ingurgitadas, sugerindo a necessidade da participação de um hospedeiro amplificador (provavelmente um roedor) no ciclo natural da riquétsia, para a sua manutenção na natureza ${ }^{3,13}$.

As características morfológicas dos estágios adultos de $A$. ovale são as seguintes ${ }^{45}$ :

Macho (Figura 3A e 3B): Sulco marginal distinto, limitando, posteriormente, todos os festões; coxa I com dois espinhos contíguos, agudos e tão longos quanto o comprimento da coxa; o externo é ligeiramente encurvado para fora e pouco mais longo que o interno, ambos cobrindo o artículo seguinte; escudo castanho com manchas acobreadas a esverdeadas; hipostômio com dentição 3/3.

Figura 3. Macho Amblyomma ovale, dorsal (A), ventral (B) (Fonte: Barros-Battesti DMB, Arzua M, Bechara GH. Carrapatos de importância medico-veterinária da Região Neotropical: Um guia ilustrado para identificação de espécies. São Paulo: Vox/ ICTTD-3; 2006. 223p.) $)^{45}$.
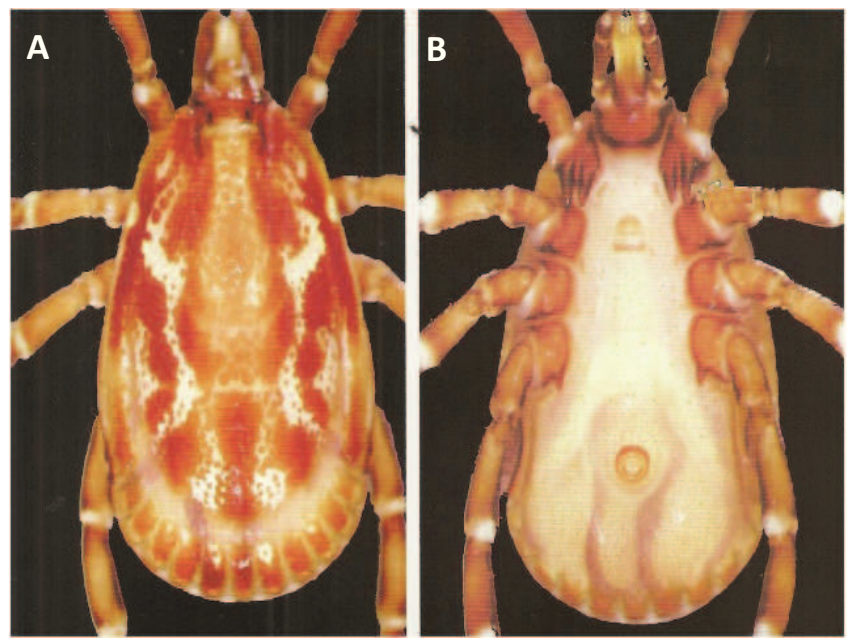

Fêmea (Figura 4A e 4B): Coxa IV com um só espinho; hipostômio com dentição 3/3; coxa I com dois espinhos longos, similares aos machos; escudo com pontuações profundas e irregularmente distribuídas, apresentando uma mancha central que vai desde a porção anterior até a posterior, e outras bem menores nos campos laterais; todas de coloração esverdeada a acobreada.

\section{Amblyomma tigrinum}

Em condições naturais, $A$. tigrinum é um carrapato de três hospedeiros; os estágios imaturos (larvas e ninfas) alimentamse, principalmente, em roedores, aves e os estádios adultos em espécies de animais da ordem Carnívora (principalmente canídeos) ${ }^{37}$. É reconhecida como uma espécie antropofílica, principalmente os estágios adultos ${ }^{39}$.

No Brasil, a distribuição geográfica desta espécie de carrapato inclui diferentes biomas: Pantanal, Cerrado, Caatinga, Mata 
Atlântica e $\mathrm{Pampa}^{46}$. Neste último, recentemente, foram coletados estágios adultos de $A$. tigrinum infectados com Rickettsia parkeri sensu stricto (taxa de infecção de $28 \%$ ) em regiões geográficas com relatos prévios de riquetsioses em humanos ${ }^{10}$. Nos Estados Unidos, Argentina e Uruguai, R. parkeri sensu stricto é o principal agente etiológico de riquetsiose associada à escara de inoculação ${ }^{19,18,19,47-49}$. Contudo, precisa-se de novos estudos com o fim de confirmar o papel da $R$. parkeri sensu stricto na etiologia das riquetsioses no Pampa brasileiro, a competência vetorial de $A$. tigrinum, e os possíveis hospedeiros amplificadores envolvidos na ecoepidemiología da doença.

Figura 4. Fêmea Amblyomma ovale, dorsal (A), ventral (B) (Fonte: Barros-Battesti DMB, Arzua M, Bechara GH. Carrapatos de importância medico-veterinária da Região Neotropical: Um guia ilustrado para identificação de espécies. São Paulo: Vox/ ICTTD-3; 2006. 223p.) ${ }^{45}$.
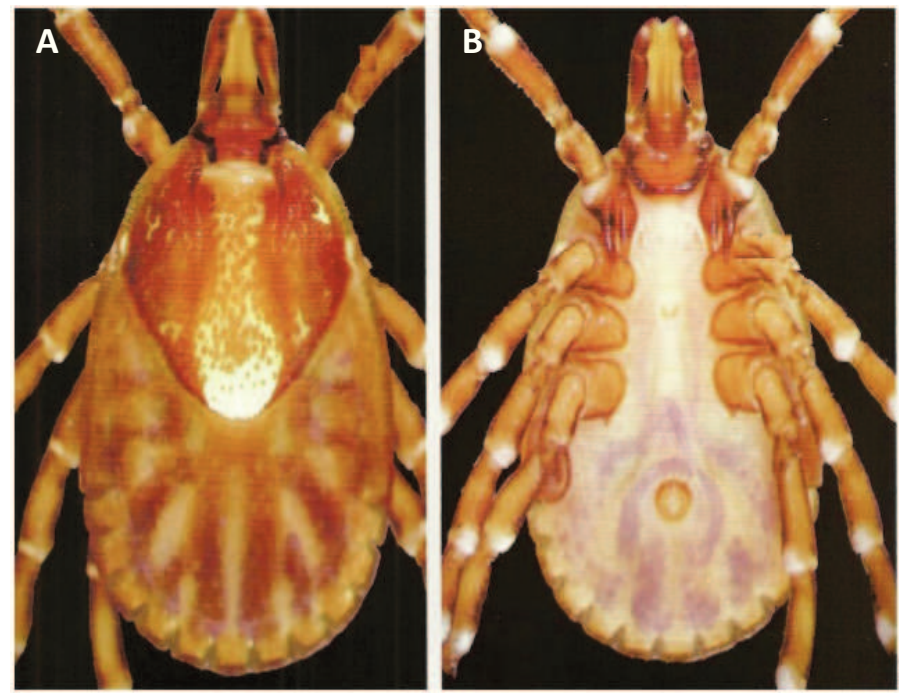

As características morfológicas dos estágios adultos de $A$. tigrinum são as seguintes ${ }^{45}$ :

Macho (Figura 5A e 5B): Sulco marginal distinto, limitando, posteriormente, todos os festões; coxa I com dois espinhos, um externo longo e um interno muito curto, quase indistinto; coxa IV com um só espinho, tão ou mais longo que o comprimento do articulo; escudo castanho com manchas esbranquiçadas; espécies pequenas; esporões nos tarsos II, III e IV; pernas IV mais robustas; escudo com listras; a banda marrom central do escudo é nitidamente interrompida na porção mediana; hipostômio com dentição 3/3.

Fêmea (Figura 6A e 6B): Coxa I com dois espinhos, porém o interno vestigial; espinho externo da coxa I longo, de comprimento ultrapassando a metade do artículo; Coxa IV com um só espinho curto; hipostômio com dentição 3/3; festões sem tubérculos nos ângulos internos; banda marrom central do escudo normalmente interrompida na porção posterior por uma mancha esbranquiçada; presença de um esporão nos prétarsos.
Figura 5. Macho Amblyomma tigrinum, dorsal (A), ventral (B) (Fonte: Barros-Battesti DMB, Arzua M, Bechara GH. Carrapatos de importância medico-veterinária da Região Neotropical: Um guia ilustrado para identificação de espécies. São Paulo: Vox/ ICTTD-3; 2006. 223p. $)^{45}$.
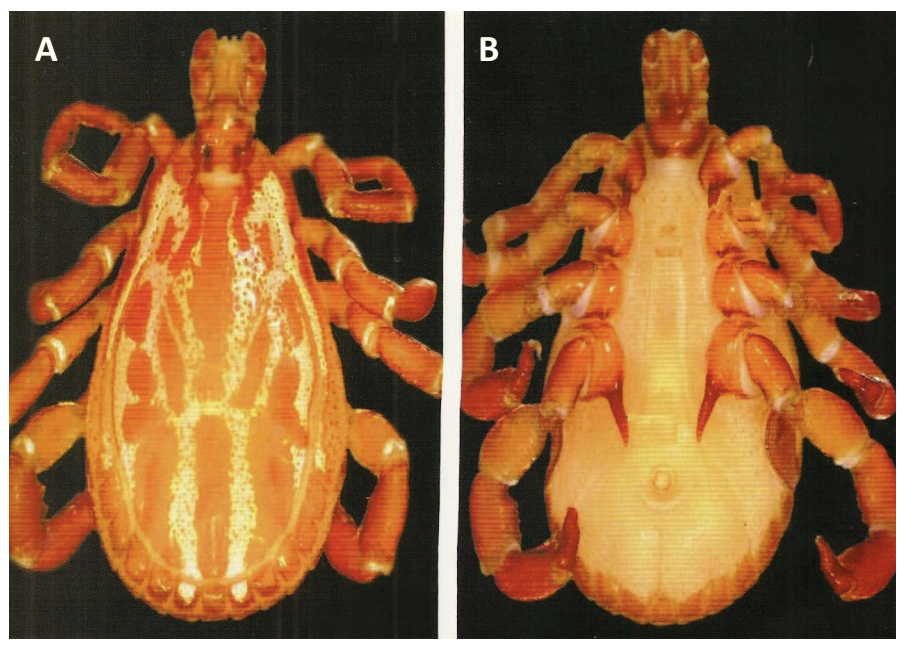

Figura 6. Fêmea Amblyomma tigrinum, dorsal (A), ventral (B) (Fonte: Barros-Battesti DMB, Arzua M, Bechara GH. Carrapatos de importância medico-veterinária da Região Neotropical: Um guia ilustrado para identificação de espécies. São Paulo: Vox/ ICTTD-3; 2006. 223p. $)^{45}$.
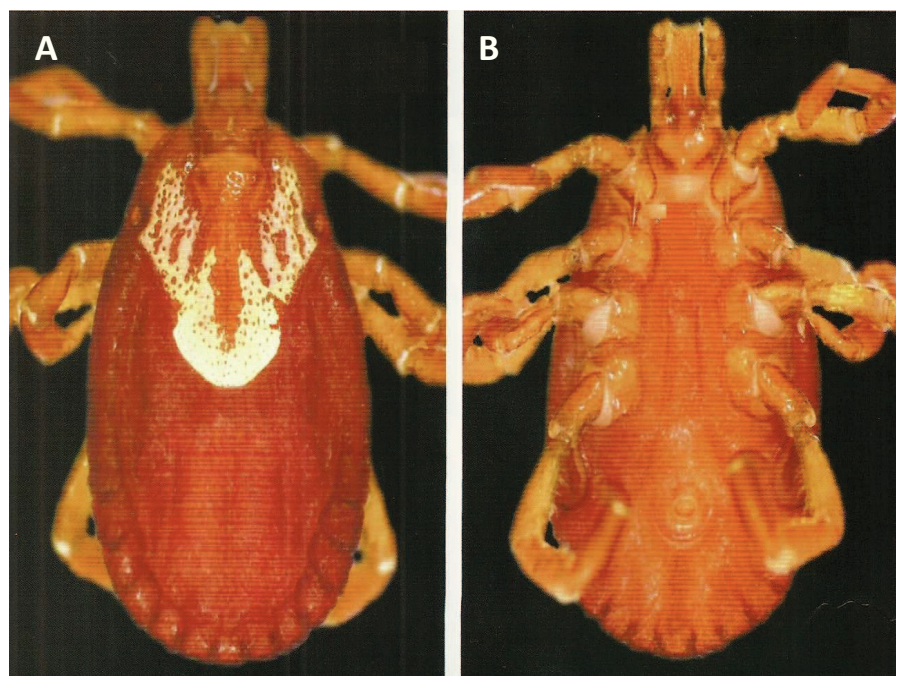

Amblyomma triste

Em condições naturais, $A$. triste é um carrapato de três hospedeiros; os estágios imaturos (larvas e ninfas) alimentamse, principalmente, em roedores e aves. No Brasil, os estádios adultos são encontrados sobretudo em cervo-dopantanal (Blastocerus dichotomus) e capivaras (Hydrochoerus hydrochaeris). Na Argentina, parasitam o cervo e os bovinos, e no Uruguai, principalmente o cão doméstico ${ }^{22}$. Nesses dois últimos países, é reconhecida como uma espécie antropofílica no estágio adulto ${ }^{22}$, embora não haja relatos de infestações em humanos por $A$. triste no Brasil. 
No Brasil, a distribuição geográfica de $A$. triste coincide com a distribuição atual de seu principal hospedeiro para o estágio adulto, o cervo-do-pantanal, o que inclui o oeste do Estado de São Paulo, noroeste de Minas Gerais, região Centro-Oeste e Rio Grande do Sul. Há registros de adultos de $A$. triste infectados com Rickettsia parkeri (taxa de infecção ao redor de $10 \%$ ) nos estados de São Paulo, Mato Grosso e Mato Grosso do Sul27,30,33. $\mathrm{Na}$ Argentina e Uruguai, $R$. parkeri também foi relatada infectando este carrapato ${ }^{17,20}$, associado a casos humanos de riquetsiose com escara de inoculação ${ }^{19,48,49}$. Contudo, são necessários novos estudos com o fim de confirmar o papel da $R$. parkeri sensu stricto na etiologia das riquetsioses no Brasil, uma vez que não há registros de parasitismo humano por $A$. triste no Brasil. Por fim, há registros de R. parkeri em Amblyomma maculatum (espécie muito próxima de $A$. triste) no Peru ${ }^{24}$ e nos Estados Unidos ${ }^{21}$, sendo que, neste último país, há vários casos humanos de riquetsiose com escara de inoculação reportados ${ }^{47}$.

As características morfológicas dos estágios adultos de $A$. triste são as seguintes ${ }^{45}$ :

Macho (Figura 7A e 7B): Sulco marginal distinto limitando, posteriormente, todos os festões; coxa I com dois espinhos menores que a altura da coxa, um dos quais, em geral, cobre o artículo seguinte, ou se ambos o cobrem, não alcançam a metade desse artículo; coxa IV com um só espinho, tão ou mais longo que o comprimento do artículo; coxa I com o espinho externo longo e o interno quase obsoleto; escudo castanho com manchas esbranquiçadas; esporões nos tarsos II, III e IV; pernas IV mais robustas; escudo com listras, a banda marrom central é francamente interrompida na porção mediana em que está localizada a fóvea; espinho da coxa IV muito longo e fino, ultrapassando o comprimento da coxa; hipostômio 3/3.

Figura 7. Macho Amblyomma triste, dorsal (A), ventral (B) (Fonte: Barros-Battesti DMB, Arzua M, Bechara GH. Carrapatos de importância medico-veterinária da Região Neotropical: Um guia ilustrado para identificação de espécies. São Paulo: Vox/ ICTTD-3; 2006. 223p. $)^{45}$.
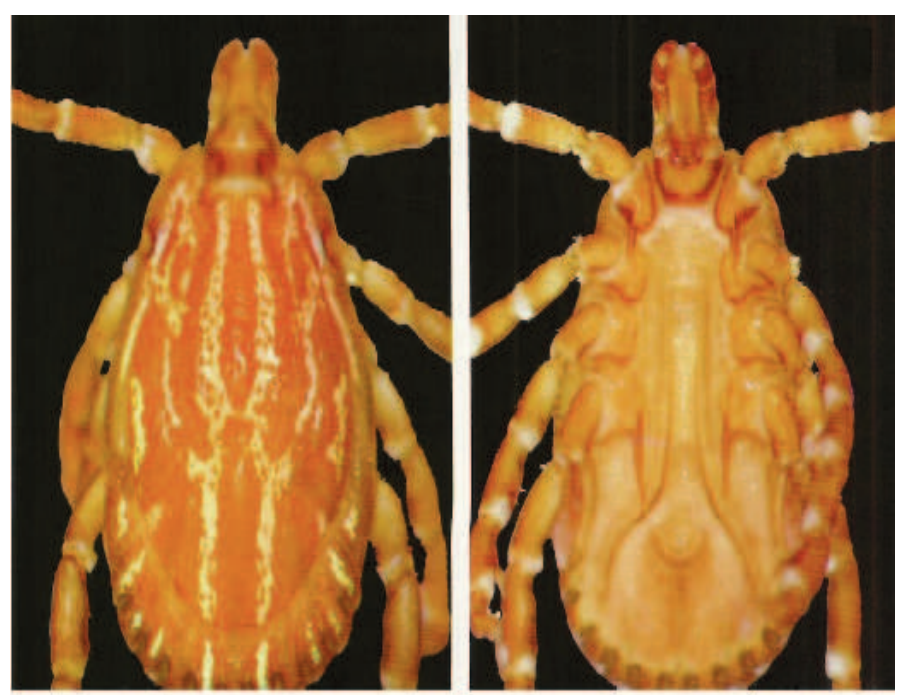

Fêmea (Figura 8A e 8B): Coxa IV com um só espinho; hipostômio 3/3; coxa I com dois espinhos, porém o interno vestigial; espinho externo da coxa I longo, de comprimento ultrapassando a metade do artículo; festões com tubérculos quitinosos nos ângulos internos; banda marrom central do escudo contínua, não sendo interrompida na porção posterior por uma mancha esbranquiçada; presença de um esporão nos pré-tarsos.

Figura 8. Fêmea Amblyomma triste, dorsal (A), ventral (B) (Fonte: Barros-Battesti DMB, Arzua M, Bechara GH. Carrapatos de importância medico-veterinária da Região Neotropical: Um guia ilustrado para identificação de espécies. São Paulo: Vox/ ICTTD-3; 2006. 223p.) $)^{45 .}$
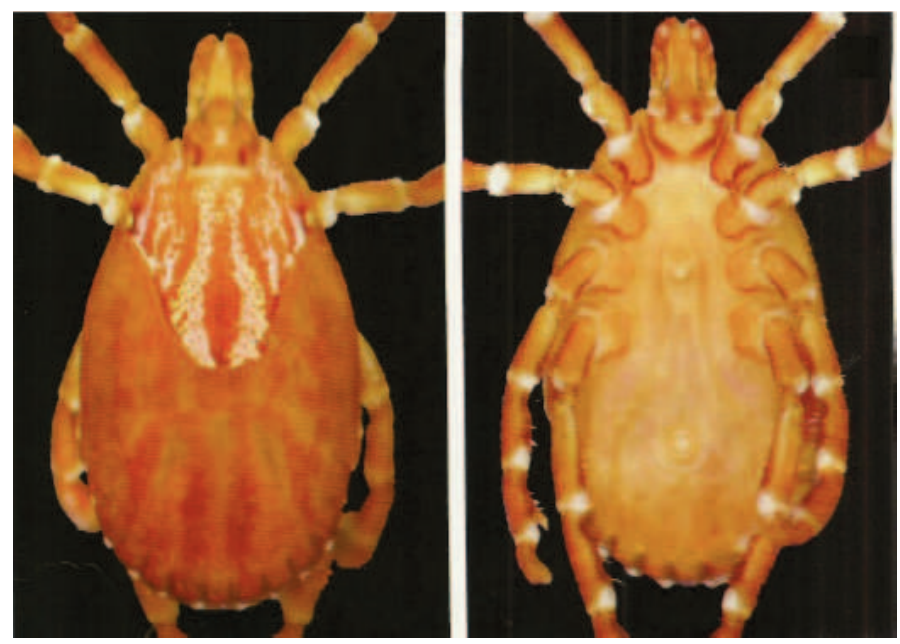

Outras espécies de carrapatos antropofílicos como Amblyomma aureolatum $^{39}$ têm sido encontrados infectados naturalmente pela Rickettsia parkeri cepa Mata Atlântica no estado de Santa Catarina, principalmente em regiões onde se encontra em simpatria com $A$. ovale ${ }^{34,50}$. Diante disso, precisa-se de novos estudos avaliando a competência vetorial de $A$. aureolatum e o seu possível papel como vetor alternativo na ecoepidemiología da riquetsiose causada por Rickettsia parkeri cepa Mata Atlântica.

\section{Manifestações clínicas}

Caracteriza-se por ser uma doença febril aguda autolimitada, de evolução leve ou moderada, sem cronicidade nem manifestações graves ou letais ${ }^{7-11}$.

Após um período de incubação de 4 a 11 dias, desde a picada do carrapato infectado, inicia-se um quadro clínico cujos sinais/ sintomas principais são febre e escara de inoculação ${ }^{7-9}$. A escara de inoculação define-se como uma lesão tipo úlcera, com centro crostoso-necrótico com halo eritematoso circundante, de 0,5 $2 \mathrm{~cm}$ de diâmetro, não dolorosa, a qual indica o ponto onde foi a picada do carrapato transmissor (Figura 9). Podem-se apresentar outros sinais e sintomas associados, tais como linfadenopatia regional ipsilateral à escara de inoculação, exantema (macular, maculopapular ou maculovesicular) principalmente em tronco e membros, mal-estar geral, cefaleia, mialgias e artralgias ${ }^{7-9}$. Sintomas respiratórios ou gastrointestinais são excepcionais ${ }^{7-9}$. 
Figura 9. Escara de inoculação em paciente com febre maculosa produzida por Rickettsia parkeri cepa Mata Atlântica. (A) 12 dias após a picada do carrapato (DAPC). (B) 14 DAPC. (C) 23 DAPC. (D) 30 DAPC (Fonte: Krawczak FS, Muñoz-Leal S, Guztzazky AC, Oliveira SV, Santos FC, Angerami RN, et al. Rickettsia sp. strain Atlantic rainforest infection in a patient from a spotted fever-endemic area in Southern Brazil. Am J Trop Med Hyg. 2016 Sep; 95(3): 551-553) ${ }^{9}$.
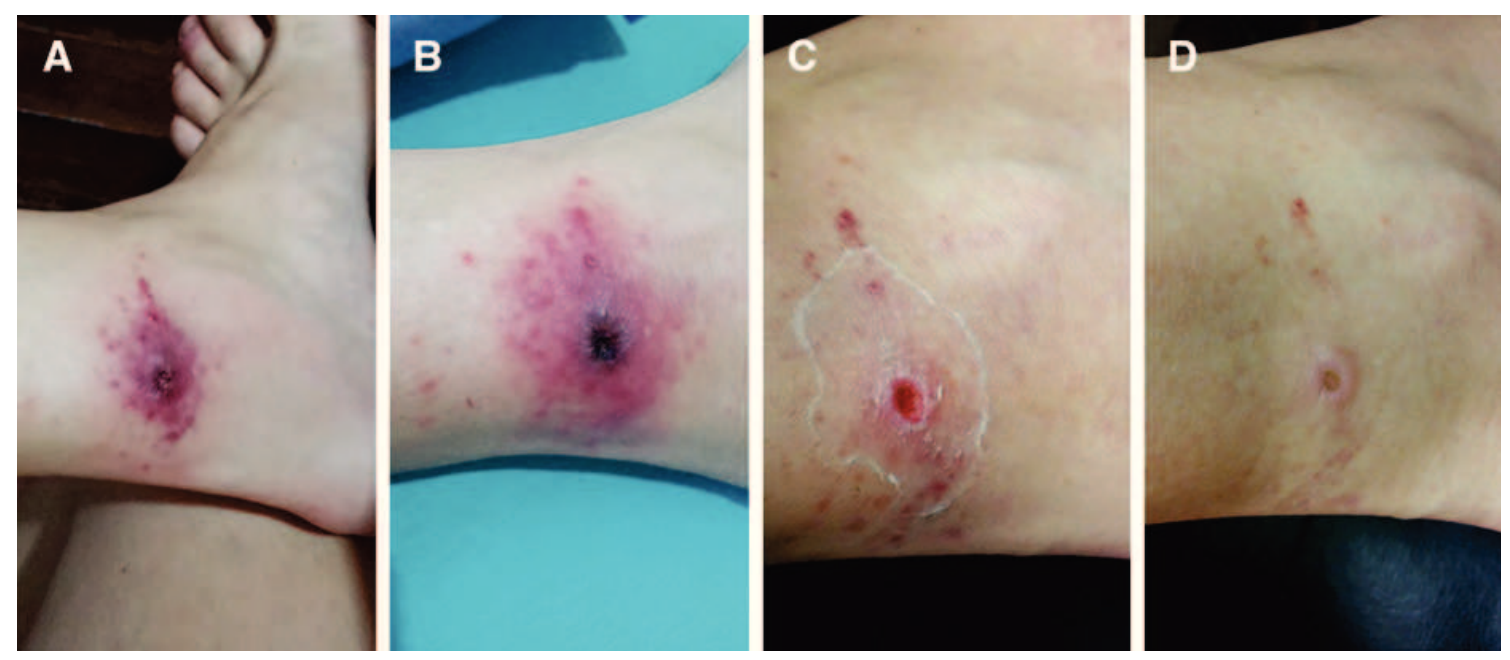

\section{Antecedentes epidemiológicos sugestivos}

Durante a abordagem dos pacientes com quadro clínico sugestivo de febre maculosa causada por R. parkeri, as seguintes informações epidemiológicas podem fortalecer a suspeita diagnóstica (Figura 10):

- Visita na mata entre uma e duas semanas antes do início da

doença.

- Contato com animais infestados por carrapatos (principalmente cães), entre uma e duas semanas antes do início da doença. - Picada prévia de carrapato (entre quatro e onze dias antes do início da doença) na região anatômica, na qual é evidente a escara de inoculação.

Figura 10. Fluxograma para suspeita clínica de febre maculosa causada por Rickettsia parkeri

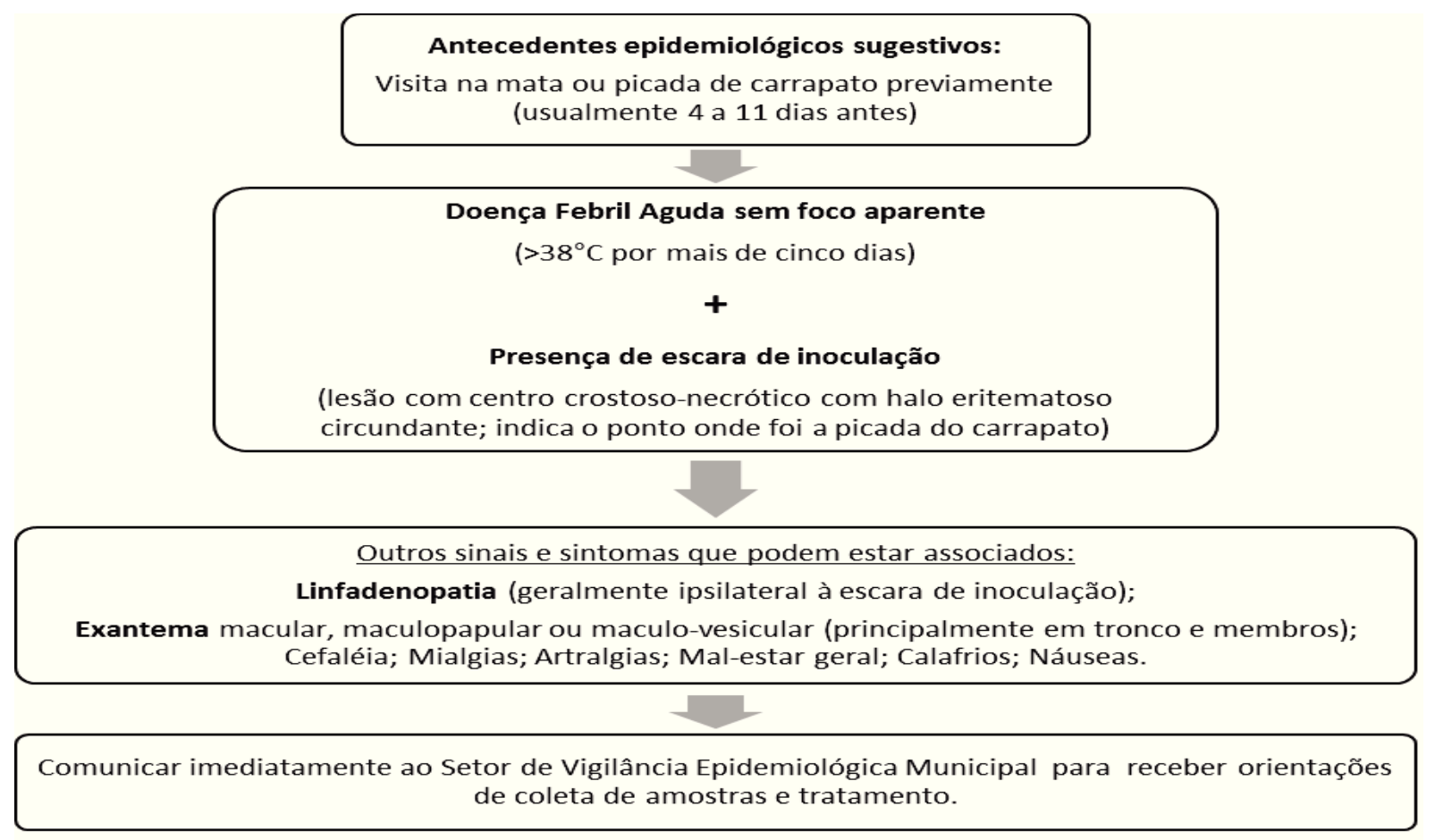




\section{Diagnóstico}

As amostras clínicas que apresentam maiores vantagens para o diagnóstico da febre maculosa causada por $R$. parkeri são o soro e a escara de inoculação (crosta da escara e/ou swab da base da escara) $)^{1,47,51,52}$. No entanto, outras amostras podem ser complementares: sangue total com anticoagulante (heparina, EDTA ou citrato), biopsia do exantema e/ou da escara de inoculação, ou o carrapato retirado do paciente (Figura 11). As amostras deveram ser coletadas de forma estéril e idealmente antes do início do tratamento antibiótico ${ }^{53}$. Na Tabela 1, apresentam-se as condições de coleta, transporte e conservação das amostras clínicas ${ }^{53}$.

Figura 11. Fluxograma de coleta e processamento de amostras para investigação laboratorial da febre maculosa causada por Rickettsia parkeri. BHI (Caldo Infusão Cérebro e Coração); RIFI (Reação de Imunofluorescência Indireta); qPCR (PCR em tempo real).

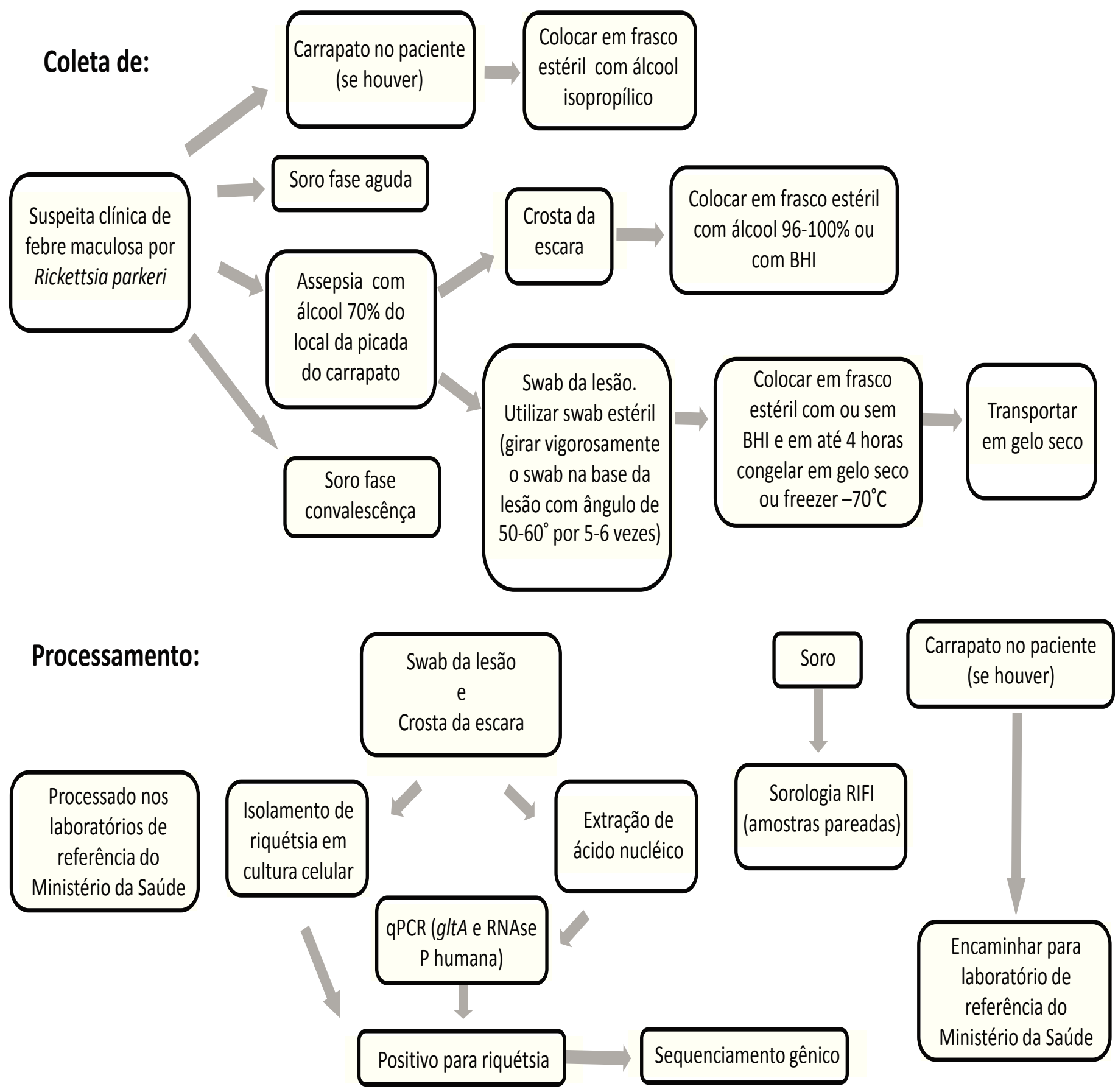


Tabela 1. Condições de coleta, transporte e conservação das amostras clínicas ${ }^{53}$.

\begin{tabular}{|c|c|c|c|c|}
\hline Amostra & Coleta de amostra & $\begin{array}{c}\text { Tempo e temperatura de } \\
\text { transporte }\end{array}$ & Conservação & $\begin{array}{c}\text { Prova } \\
\text { diagnostica }\end{array}$ \\
\hline $\begin{array}{l}\text { Sangue total/camada } \\
\text { leucocitária }\end{array}$ & $\begin{array}{l}\text { Tubo com EDTA o citrato } \\
(3-5 \mathrm{~mL})\end{array}$ & $\begin{array}{l}<24 \mathrm{~h}, 2-8 \circ \mathrm{C} \\
>24 \mathrm{~h},-20^{\circ} \mathrm{C}\end{array}$ & $>24 \mathrm{~h},-20 \circ \mathrm{C}$ & PCR \\
\hline $\begin{array}{l}\text { Sangue total/camada } \\
\text { leucocitária }\end{array}$ & $\begin{array}{l}\text { Tubo com Heparina (3-5 } \\
\mathrm{mL} \text { ) }\end{array}$ & $>24 \mathrm{~h}$, gelo seco & $\begin{array}{l}\text { Processar imediatamente ou } \\
\text { congelar a }-80^{\circ} \mathrm{C}\end{array}$ & Cultivo \\
\hline Soro* & $\begin{array}{l}\text { Tubo com gel separador } \\
\text { de soro/ tubo com } \\
\text { anticoagulante } \\
\text { (centrifugar) }\end{array}$ & $<24$ h, $2-8^{\circ} \mathrm{C}$ & $>24 \mathrm{~h},-20^{\circ} \mathrm{C}$ & RIFI/PCR \\
\hline $\begin{array}{l}\text { Outros fluidos (Liquor, } \\
\text { liquido pleural) }\end{array}$ & Tubo estéril & $\begin{array}{l}<24 \mathrm{~h}, 2-8 \circ \mathrm{C} \\
>24 \mathrm{~h},-20^{\circ} \mathrm{C}\end{array}$ & $\begin{array}{l}>24 \mathrm{~h},-20 \circ \mathrm{C} \\
\text { Processar imediatamente ou } \\
\text { congelar a }-80^{\circ} \mathrm{C}\end{array}$ & $\begin{array}{l}\text { PCR } \\
\text { Cultivo }\end{array}$ \\
\hline $\begin{array}{l}\text { Biopsia de pele ou escara, e } \\
\text { tecido de órgão (autopsia) }\end{array}$ & $\begin{array}{l}\text { Tubo estéril, } \\
\text { O tecido deve ser } \\
\text { enviado em seco }\end{array}$ & $\begin{array}{l}>24 \mathrm{~h},-20 \circ \mathrm{C} \\
>24 \mathrm{~h} \text {, gelo seco }\end{array}$ & $\begin{array}{l}>24 \mathrm{~h},-20 \circ \mathrm{C} \\
\text { Processar imediatamente ou } \\
\text { congelar a }-80^{\circ} \mathrm{C}\end{array}$ & $\begin{array}{l}\text { PCR } \\
\text { Cultivo }\end{array}$ \\
\hline Swab da base da escara ${ }^{a *}$ & $\begin{array}{l}\text { Tubo estéril, o swab } \\
\text { deve ser enviado em } \\
\text { seco }\end{array}$ & 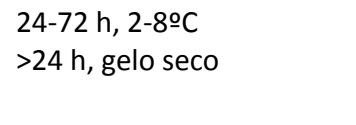 & $\begin{array}{l}2-8 \circ \mathrm{C} \\
\text { Processar imediatamente ou } \\
\text { congelar a }-80 \circ \mathrm{C}\end{array}$ & $\begin{array}{l}\text { PCR } \\
\text { Cultivo }\end{array}$ \\
\hline Crosta da escara* & Tubo estéril & $\begin{array}{l}24-48 \mathrm{~h}, 2-8 \circ \mathrm{C} \\
>48 \mathrm{~h},-20 \circ \mathrm{C} \\
>48 \mathrm{~h} \text {, etanol } 70-95 \% \\
>48 \mathrm{~h} \text {, gelo seco }\end{array}$ & $\begin{array}{l}>48 \mathrm{~h},-20 \circ \mathrm{C} \\
>48 \mathrm{~h},-20 \circ \mathrm{C} \\
>48 \mathrm{~h} \text {, etanol } 70-95 \% \\
\text { Processar imediatamente ou } \\
\text { congelar a }-80 \circ \mathrm{C}\end{array}$ & $\begin{array}{l}\text { PCR } \\
\text { PCR } \\
\text { PCR } \\
\text { Cultivo }\end{array}$ \\
\hline $\begin{array}{l}\text { Tecidos fixados em } \\
\text { formalina, embebidos em } \\
\text { parafina }\end{array}$ & Tubo/cassete & Temperatura ambiente & Temperatura ambiente & $\mathrm{PCR} / \mathrm{IHQ}$ \\
\hline Carrapato & Tubo estéril & 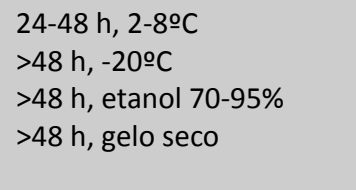 & $\begin{array}{l}>48 \mathrm{~h},-20 \circ \mathrm{C} \\
>48 \mathrm{~h},-20^{\circ} \mathrm{C} \\
>48 \mathrm{~h} \text {, etanol } 70-95 \% \\
\text { Processar imediatamente o congelar } \\
\text { a }-80 \cong \mathrm{C}\end{array}$ & $\begin{array}{l}\text { PCR } \\
\text { PCR } \\
\text { PCR } \\
\text { Cultivo }\end{array}$ \\
\hline
\end{tabular}

RIFI (Reação de imunofluorescência indireta); PCR (Reação em cadeia da polimerase); IHQ (Imuno-histoquimica)

*Amostras que apresentam maiores vantagens para o diagnóstico das riquetsioses associadas à escara de inoculação.

a Retirar a crosta e fazer um esfregaço com movimentos circulares sobre a base da escara utilizando o swab.

\section{Diagnóstico laboratorial}

\section{Reação de imunofluorescência indireta (RIFI)}

O método sorológico é o mais utilizado para o diagnóstico da febre maculosa e considerado o padrão-ouro ${ }^{54}$. Em geral, os anticorpos são detectados a partir do 70 ao 10ㅇ dia da infecção. Os anticorpos IgM podem apresentar reação cruzada com outras doenças (dengue, leptospirose, entre outras) e, portanto, devem ser analisados com critério. Já os anticorpos IgG aparecem pouco tempo depois dos IgM e são os mais específicos e indicados para a interpretação diagnóstica ${ }^{54}$.

O diagnóstico laboratorial por RIFI é estabelecido pelo aparecimento de anticorpos específicos, que aumentam em título com a evolução da doença, no soro de pacientes. Devese coletar a primeira amostra de soro nos primeiros dias da doença (fase aguda) e a segunda amostra de 14 a 21 dias após 
a primeira coleta. A presença de um aumento de quatro vezes nos títulos de anticorpos, observado em amostras pareadas de soro, é o requisito para confirmação diagnóstica pela sorologia. O processamento das amostras deve ser, preferencialmente pareado e nas mesmas condições e analisadas pelo mesmo operador. Exemplos de interpretação de resultados de RIFI estão demonstrados na Tabela 2. O resultado deve ser interpretado dentro de um contexto clínico e epidemiológico ${ }^{54}$.

Tabela 2. Exemplos de interpretação de resultados de Reação de imunofluorescência indireta (RIFI) para riquétsias do grupo febre maculosa em duas amostras de soro ${ }^{54}$.

\begin{tabular}{|c|c|c|}
\hline $\begin{array}{l}\text { Primeira } \\
\text { amostra }^{\text {a }}\end{array}$ & Segunda amostra ${ }^{b}$ & $\begin{array}{l}\text { Interpretação e } \\
\text { comentário }\end{array}$ \\
\hline Não reagente & Não reagente & Descartado \\
\hline Não reagente & 64 & $\begin{array}{l}\text { Verificar possibilidade } \\
\text { de surgimento/aumento } \\
\text { tardio de anticorpos }{ }^{c}\end{array}$ \\
\hline Não reagente & 128 & Confirmado \\
\hline 64 & 64 & $\begin{array}{l}\text { Verificar possibilidade } \\
\text { de surgimento/aumento } \\
\text { tardio de anticorpos }{ }^{c}\end{array}$ \\
\hline 128 & 256 & $\begin{array}{l}\text { Verificar possibilidade } \\
\text { de surgimento/aumento } \\
\text { tardio de anticorpos }{ }^{c}\end{array}$ \\
\hline 128 & 512 & Confirmado \\
\hline 256 & 512 & $\begin{array}{l}\text { Verificar possibilidade } \\
\text { de surgimento/aumento } \\
\text { tardio de anticorpos }{ }^{c}\end{array}$ \\
\hline 256 & 1024 & Confirmado \\
\hline \multicolumn{3}{|c|}{$\begin{array}{l}\text { a Primeira amostra colhida no início dos sintomas. } \\
\text { b Segunda amostra colhida de } 14 \text { a } 21 \text { dias após a primeira coleta. } \\
\text { ' Diante da possibilidade de retardo na cinética de anticorpos, eventualmente } \\
\text { o surgimento da soroconversão pode ocorrer mais tardiamente. Assim, diante } \\
\text { de um caso clínico-epidemiológico compatível, recomenda-se fortemente que } \\
\text { uma terceira amostra seja coletada } 14 \text { dias após a segunda. Esta recomendação } \\
\text { deve ser reforçada, por exemplo, diante de um paciente cujo tratamentc } \\
\text { com antibioticoterapia específica foi instituído precocemente. Caso a terceira } \\
\text { amostra permaneça sem aumento do título, o caso deve ser descartado. }\end{array}$} \\
\hline
\end{tabular}

Técnicas de biologia molecular - reação em cadeia da polimerase (PCR)

Realizada em amostras de escara de inoculação (crosta da escara e/ou swab da base da escara), sangue, soro, coágulos formados após centrifugação do sangue coletado, tecido de biopsia ou necrópsia. Apesar de ser um método rápido, não possui um padrão específico, e a sensibilidade e a especificidade diagnóstica pode variar entre os testes e o tipo de amostra colhida. As técnicas de biologia molecular possibilitam a melhor e mais adequada caracterização da espécie específica do agente etiológico (Rickettsia spp.). Normalmente, amostras contendo células endoteliais (ex. pele, órgãos internos) apresentam maior sensibilidade diagnóstica, uma vez que as riquétsias patogênicas se multiplicam, principalmente, nessas células. Por outro lado, amostras de sangue, soro ou coágulo possuem menor sensibilidade na PCR, estando o resultado positivo condicionado ao grau de destruição endotelial (que proporciona a liberação de um grande número de riquétsias na circulação sanguínea) ${ }^{54}$.

\section{Isolamento}

Cultura com isolamento da riquétsia é o método diagnóstico ideal. Deve ser realizado em laboratórios com nível de biossegurança 3 (NB3). O isolamento do agente etiológico é feito a partir da escara de inoculação (crosta da escara e/ou swab da base da escara), sangue (coágulo) ou de fragmentos de tecidos obtidos por biópsia ou de órgãos obtidos por necrópsia, além do carrapato retirado do paciente ${ }^{54}$.

\section{Imuno-histoquímica (IHQ)}

Realizada em amostras de tecidos obtidas em biopsia de lesões de pele de pacientes infectados, em especial os graves, ou em material de necrópsia, como fragmentos de pulmão, fígado, baço, coração, músculos e cérebro. A imuno-histoquímica em lesões vasculíticas de pele ou da escara de inoculação é considerada o método mais sensível para a confirmação de febre maculosa na fase inicial da doença ${ }^{54}$.

\section{Exames inespecíficos e complementares}

No hemograma, pode-se evidenciar plaquetopenia discreta e leucopenia discreta. As aminotransferases (ALT/TGP e AST/TGO) podem estar moderadamente aumentadas ${ }^{47}$.

\section{Definição de caso}

\section{Caso suspeito}

Indivíduo que apresente síndrome febril aguda sem foco aparente, escara de inoculação associada ou não à linfadenopatia regional ipsilateral, erupção cutânea, mal-estar geral, cefaleia, mialgias, artralgias, e que tenha relatado história de picada de carrapato e/ou contato com animais domésticos (principalmente cães) e/ou ter frequentado área de mata nos últimos 12 dias.

\section{Caso confirmado}

Indivíduo cujos sinais, sintomas e antecedentes epidemiológicos atendem à definição de caso suspeito, no qual a infecção por riquétsias do grupo da febre maculosa tenha sido confirmada laboratorialmente, em pelo menos uma das seguintes provas diagnósticas: (i) soroconversão por meio da RIFI em duas amostras de soro; e/ou (ii) técnicas de biologia molecular - PCR (detecção do agente etiológico); e/ou (iii) imuno-histoquímica reagente para antígenos específicos de Rickettsia do grupo da febre maculosa; e/ou (iv) isolamento em cultura do agente etiológico. 


\section{Caso descartado}

Caso suspeito com diagnóstico confirmado para outra doença ou sem dados suficientes para confirmar o diagnóstico de febre maculosa causada por Rickettsia parkeri.

\section{Diagnósticos diferenciais}

O principal diagnóstico diferencial em pacientes com febre, lesão sugestiva de escara de inoculação e linfadenopatia regional é a tularemia ulceroglandular. Outro diagnóstico diferencial, no qual se apresenta escara e linfadenopatia, porem a febre é infrequente, é o Antraz cutâneo (lesão não dolorosa com edema importante ao redor da escara). Por fim, os principais diagnósticos diferenciais em pacientes sem febre nem linfadenopatias, porém com escara associada a sinais inflamatórios locais, são: ectima (Figura 12 A e B), loxoscelismo (lesão dolorosa, bordas irregulares e sem edema associado) e picada de carrapatos de modo geral ${ }^{55}$ (Figura $12 \mathrm{C}$ ), destacandose os carrapatos do gênero Ornithodoros (picada dolorosa; formação de vesículas e necrose) ${ }^{56,57}$ (Figura 12 D e E).

Figura 12. A e B. Ectima. (Fonte: autor, Álvaro A. Faccini-Martínez). C. Lesões cutâneas por picada de carrapato Amblyomma sp. ${ }^{55}$ (A imagem original foi publicada e gentilmente cedida pela Revista da Sociedade Brasileira de Medicina Tropical; Comunicação: Ramos RAN, Galindo MKF, Santana MA, Faustino MAG, Alves LC, 2010. Parasitismo em humano por Amblyomma sp (Acari: Ixodidae), na cidade de Recife, estado de Pernambuco. Rev Soc Bras Med Trop. 2010;43(5):594-5). D e E. Lesão induzida por picada de Ornithodoros brasiliensis. Em D. Lesão no peito do pé - três semanas após picada do carrapato. Em E. Lesão no calcanhar - duas semanas após picada do carrapato (Fonte: Reck J, Marks FS, Guimaraes JA, Termignoni C, Martins JR. Epidemiology of Ornithodoros brasiliensis (mouro tick) in the Southern Brazilian highlands and the description of human and animal retrospective cases of tick parasitism. Ticks Tick Borne Dis. 2013 Fev; 4(1-2): 101-109) ${ }^{56}$.
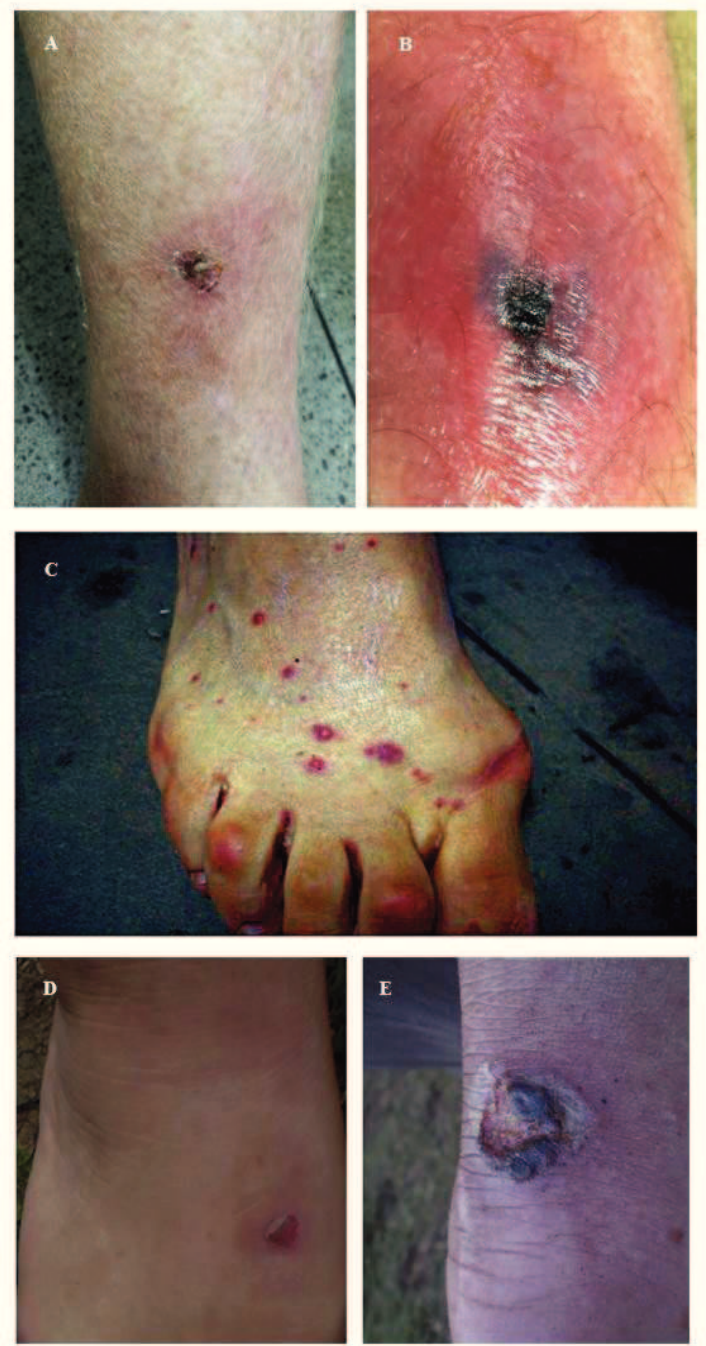


\section{Tratamento}

As evidências clínicas, microbiológicas e epidemiológicas estabelecem que a doxiciclina é o antimicrobiano de escolha para terapêutica de todos os casos suspeitos de riquetsioses, independentemente da faixa etária e da gravidade da doença ${ }^{54}$. Em geral, quando a terapêutica apropriada é iniciada, a febre tende a desaparecer entre 24 e 72 horas após o início da terapia.

A terapêutica é empregada rotineiramente por um período de sete dias, ou devendo ser mantida por três dias, após o término da febre. A dose de doxiciclina para adultos ou crianças com peso acima de $45 \mathrm{~kg}$ é de $100 \mathrm{mg}$ de 12 em 12 horas, por via oral. Para crianças com peso inferior a $45 \mathrm{~kg}$, a dose recomendada é $2,2 \mathrm{mg} / \mathrm{kg}$ de $12 \mathrm{em} 12$ horas por via oral ${ }^{54}$.

A claritromicina tem sido apontada como antimicrobiano de segunda escolha no tratamento das riquetsioses não graves, principalmente em crianças e mulheres grávidas ${ }^{58}$. A dose de claritromicina para adultos é de $500 \mathrm{mg}$ de 12 em 12 horas, e, para crianças, $15 \mathrm{mg} / \mathrm{kg}$ de 12 em 12 horas, por via oral, durante sete dias $^{58}$.

A partir da suspeita de riquetsiose, a terapêutica com antibióticos deve ser iniciada imediatamente, não se devendo esperar a confirmação laboratorial do caso.

Não é recomendada a antibioticoterapia profilática para indivíduos assintomáticos que tenham sido recentemente picados por carrapatos.

\section{Vigilância e notificação}

Todo caso suspeito de febre maculosa causada por $R$. parkeri requer notificação compulsória e imediata às três esferas do Sistema Único de Saúde brasileiro. Essa notificação deve ser registrada no Sistema de Informação de Agravos de Notificação (SINAN) por meio do preenchimento da Ficha de Investigação Epidemiológica (FIE) da febre maculosa, indicando no campo de observações da FIE a presença da escara de inoculação ${ }^{54}$.

\section{Investigação do caso}

Deve-se iniciar a investigação imediatamente após a notificação, para permitir que as medidas de controle e prevenção de novos casos possam ser adotadas em tempo oportuno. Cabe à equipe de investigação confirmar a existência de amostras e encaminhar providências quanto à coleta dos espécimes clínicos necessários para o diagnóstico laboratorial, e reunir dados clínicos e epidemiológicos de acordo com as normas estabelecidas ${ }^{54}$.

O profissional de saúde deverá levantar dados junto ao paciente e aos familiares; consultar prontuário e, se possível, entrevistar o médico para completar as informações clínicas sobre o paciente e definir se o quadro apresentado é compatível com a doença ${ }^{54}$.

O instrumento de coleta de dados é a FIE da febre maculosa, padronizada para utilização em todo o país. Todos os campos deverão ser, criteriosamente, preenchidos, mesmo quando a informação for negativa. Informações clínicas, epidemiológicas e laboratoriais que não estejam contempladas na FIE devem ser descritas no campo de observações da $\mathrm{FIE}^{54}$.

\section{Investigação do ambiente}

Para a identificação da área de transmissão devem-se verificar os locais de residência, trabalho ou lazer que correspondem às áreas de provável transmissão da febre maculosa. Observar se existe a possibilidade de o caso ter entrado em contato com carrapatos ou áreas com criação de animais domésticos e se frequentou áreas rurais e silvestres. É indicado fazer a investigação epidemiológica para buscar estabelecer os mecanismos causais de transmissão da doença e extensão da área de transmissão. Para isso, é importante realizar a coleta de carrapatos nos humanos quando possível ou nos ambientes, a fim de caracterizar as espécies de carrapatos existentes, e, se possível, o isolamento das riquétsias circulantes ${ }^{54,59}$.

\section{Encerramento de caso}

O caso de febre maculosa causada por $R$. parkeri deve ser encerrado, oportunamente, em até 60 dias da notificação no SINAN. A classificação final do caso deve seguir os critérios descritos no item Definição de caso.

\section{Controle e prevenção}

As principais atividades preventivas na febre maculosa causada por $R$. parkeri são aquelas voltadas às ações educativas, informando à população sobre características clínicas da doença, o acesso às unidades de saúde e os serviços de atendimento médico, caracterização e informação das áreas de risco para infecção, entendimento do ciclo do vetor e o provimento das orientações técnicas e gerais à população, buscando-se evitar o contato com os potenciais vetores e o adoecimento ${ }^{54}$.

\section{Medidas de biossegurança}

Recomenda-se o uso de vestimentas que evitem o contato com os carrapatos, e que, preferencialmente, sejam de cor clara, a fim de facilitar a visualização do vetor. A parte inferior da calça deve ser inserida dentro das meias. Vedar os sapatos, as meias e as calças com fita adesiva também pode evitar que os carrapatos entrem em contato. Repelentes podem ser aplicados nas roupas e nos calçados. Vetores detectados no corpo devem ser coletados com o auxílio de pinça ou utilizandose fita adesiva e não devem ser esmagados com as unhas, pois ele pode liberar as bactérias e contaminar partes do corpo com lesões. Também é recomendado examinar o próprio corpo frequentemente, a fim de verificar a presença de carrapatos e 
retirá-los, preferencialmente, com o auxílio de pinça ${ }^{54}$.

\section{CONSIDERAÇÕES FINAIS}

A febre maculosa causada por $R$. parkeri é uma doença emergente no Brasil que ainda não tem sua história natural bem caracterizada. Os poucos casos clínicos descritos até hoje inviabilizam análises robustas da sua patogênese.

Desta forma, essa revisão busca dar subsídio preliminar e apoio na investigação epidemiológica dessa nova casuística da febre maculosa. Os profissionais de saúde deverão considerar aspectos adicionais aos que foram contemplados aqui, já que muitos destes podem ainda ser desconhecidos.

A descrição de novos casos clínicos poderá aportar informações que irão melhorar o entendimento dessa doença. É necessário investimento em pesquisa e vigilância epidemiológica para oportunizar a caracterização da febre maculosa causada por $R$. parkeri no Brasil.

Dada a menor gravidade, é possível que a febre maculosa causada por $R$. parkeri não seja corretamente identificada, o que impossibilita avaliar a real magnitude dessa doença em território brasileiro.

\section{REFERÊNCIAS}

1. Parola P, Paddock CD, Socolovschi C, Labruna MB, Mediannikov O, Kernif T, et al. Update on tick-borne rickettsioses around the world: a geographic approach. Clin Microbiol Rev. 2013;26(4):657-702. doi: 10.1128/CMR.00032-13. PubMed PMID: 24092850

2. Fang R, Blanton LS, Walker DH. Rickettsiae as Emerging Infectious Agents. Clin Lab Med. 2017;37(2):383-400. doi: 10.1016/j.cll.2017.01.009. PubMed PMID: 28457356.

3. Szabó MP, Pinter A, Labruna MB. Ecology, Biology and distribution of spottedfever tick vectors in Brazil. Front Cell Infect Microbiol. 2013;3:27. doi: 10.3389/ fcimb.2013.00027. PubMed PMID: 23875178.

4. Faccini-Martínez ÁA, García-Álvarez L, Hidalgo M, Oteo JA. Syndromic classification of rickettsioses: an approach for clinical practice. Int J Infect Dis 2014; 28:126-139. doi: 10.1016/j.ijid.2014.05.025. PubMed PMID: 25242696.

5. de Oliveira SV, Guimarães JN, Reckziegel GC, Neves BM, Araújo-Vilges KM, Fonseca LX, et al. An update on the epidemiological situation of spotted fever in Brazil. J Venom Anim Toxins Incl Trop Dis. 2016; 22(1):22. doi: http://dx.doi. org/10.1186/s40409-016-0077-4.

6. Nieri-Bastos FA, Marcili A, Sousa R, Paddock CD, Labruna MB. Phylogenetic evidence for the existence of multiple strains of Rickettsia parkeri in the new world. Appl Environ Microbiol. 2018; 84(8): e02872-17.

7. Spolidorio MG, Labruna MB, Mantovani E, Brandao PE, Richtzenhain LJ, Yoshinari NH. Novel spotted fever group rickettsiosis, Brazil. Emerg Infect Dis. 2010; 16(3): 521-523.

8. Silva N, Eremeeva ME, Rozental T, Ribeiro GS, Paddock CD, Ramos EA, et al. Eschar-associated spotted fever rickettsiosis, Bahia, Brazil. Emerg Infect Dis. 2011; 17(2):275-278. doi: 10.3201/eid1702.100859.

9. Krawczak FS, Muñoz-Leal S, Guztzazky AC, Oliveira SV, Santos FC, Angeram $\mathrm{RN}$, et al. Rickettsia sp. strain Atlantic rainforest infection in a patient from a spotted fever-endemic area in Southern Brazil. Am J Trop Med Hyg. 2016 Sep; 95(3): 551-553. doi: 10.4269/ajtmh.16-0192.

10. Weck B, Dall'Agnol B, Souza U, Webster A, Stenzel B, Klafke G, et al. Spotted fever group Rickettsia in the Pampa Biome, Brazil, 2015-2016. Emerg Infect Dis. 2016; 22(11): 2014-2016. doi: 10.3201/eid2211.160859.

11. Angerami RN, Silva AM, Nascimento EM, Colombo S, Wada MY, dos Santos FC et al. Brazilian spotted fever: two faces of the same disease? A comparative study of clinical aspects between an old and a new endemic area in Brazil. Clin Microbiol Infect. 2009; 2:207-208. doi: 10.1111/j.1469-0691.2008.02160.x.

12. Rother ET. Systematic literature review $X$ narrative review. Acta Paul Enfer. 2007 Apr-Jun; 20(2): v-vi. doi: http://dx.doi.org/10.1590/S0103-

\section{1}

13. Krawczak FS, Agostinho WC, Polo G, Moraes-Filho J, Labruna MB. Comparative evaluation of Amblyomma ovale Ticks infected and noninfected by Rickettsia sp. strain Atlantic rainforest, the agent of an emerging rickettsiosis in Brazil. Ticks Tick Borne Dis. 2016 Apr; 7(3): 502-507. doi: 10.1016/j.ttbdis.2016.02.007.

14. Oliveira SV. Regarding the ecoepidemiology of a tick-borne spotted fever southernmost state of Brazil. Ann Clin Cytol Pathol. 2016; 3(1):1048.

15. Oliveira SV. Tick-borne spotted fever in the northeast of Brazil: the series of cases a new endemic area. Rev Med UFC. 2016; 56(2): 8-9. doi: http://dx.doi. org/10.20513/2447-6595.2016v56n2p8-9.

16. Romer Y, Nava S, Govedic F, Cicuttin G, Denison AM, Singleton J, et al. Rickettsia parkeri rickettsiosis in different ecological regions of Argentina and its association with Amblyomma tigrinum as a potential vector. Am J Trop Med Hyg. 2014; 91(6): 1156-1160. doi: 10.4269/ajtmh.14-0334.

17. Venzal JM, Portillo A, Estrada-Peña A, Castro O, Cabrera PA, Oteo JÁ. Rickettsia parkeri in Amblyomma triste from Uruguay. Emerg Infect Dis. 2004; 10(8): 1493-1495. PubMed PMID: 15496258.

18. Pacheco RC, Venzal JM, Richtzenhain LJ, Labruna MB. Rickettsia parkeri in Uruguay. Emerg Infect Dis. 2006; 12(11): 1804-1805. doi: 10.3201/ eid1211.060577.

19. Romer Y, Seijo AC, Crudo F, Nicholson WL, Varela-Stokes A, Lash RR, et al. Rickettsia parkeri rickettsiosis, Argentina. Emerg Infect Dis. 2011; 17(7): 11691173. doi: 10.3201/eid1707.101857.

20. Nava S, Elshenawy Y, Eremeeva ME, Sumner JW, Mastropaolo M, Paddock CD. Rickettsia parkeri in Argentina. Emerg Infect Dis. 2008; 14(12): 1894-1897. doi: $10.3201 /$ eid1412.080860.

21. Paddock CD, Goddard J. The evolving medical and veterinary importance of the gulf coast tick (Acari: Ixodidae). J Med Entomol. 2015; 52(2): 230-252. doi: 10.1093/jme/tju022.

22. Nava S, Venzal JM, González-Acuña D, Martins TF, Guglielmone AA. Ticks of the Southern Cone of America. Diagnosis, Distribution, and Hosts with Taxonomy, Ecology and Sanitary Importance. London: Elsevier; 2017. 372 p.

23. Londoño AF, Díaz FJ, Valbuena G, Gazi M, Labruna MB, Hidalgo M, et al. Infection of Amblyomma ovale by Rickettsia sp. strain Atlantic rainforest, Colombia. Ticks Tick Borne Dis. 2014; 5(6): 672-675. doi: 10.1016/j. ttbdis.2014.04.018.

24. Flores-Mendoza C, Florin D, Felices V, Pozo EJ, Graf PC, Burrus RG, et al. Detection of Rickettsia parkeri from within Piura, Peru, and the first reported 
presence of Candidatus Rickettsia andeanae in the tick Rhipicephalus sanguineus. Vect Bor Zoon Dis. 2013; 13(7):505-508. doi: 10.1089/vbz.2012.1028.

25. Moerbeck L, Vizzoni VF, Machado-Ferreira E, Cavalcante RC, Oliveira SV, Soares CA, et al. Rickettsia (Rickettsiales: Rickettsiaceae) Vector Biodiversity in High Altitude Atlantic Forest Fragments Within a Semiarid Climate: A New Endemic Area of Spotted-Fever in Brazil. J Med Entomol. 2016 Nov; 53(6): 1458 1466. doi: 10.1093/jme/tjw121.

26. Nieri-Bastos FA, Horta MC, Barros-Battesti DM, Moraes-Filho J, Ramirez DG, Martins TF, et al. Isolation of the pathogen Rickettsia sp. strain Atlantic rainforest from its presumed tick vector, Amblyomma ovale (Acari: Ixodidae), from two areas of Brazil. J Med Entomol. 2016 Jul; 53(4): 977-981. doi:10.1093/ jme/tjw062.

27. Melo AL, Alves AS, Nieri-Bastos FA, Martins TF, Witter R, Pacheco TA, et al. Rickettsia parkeri infecting free-living Amblyomma triste ticks in the Brazilian Pantanal. Ticks Tick Borne Dis. 2015 Apr; 6(3): 237-241. doi: 10.1016/j. ttbdis.2015.01.002

28. Melo AL, Witter R, Martins TF, Pacheco TA, Alves AS, Chitarra CS, et al. A survey of tick-borne pathogens in dogs and their ticks in the Pantanal biome, Brazil. Med Vet Entomol. 2016 Mar; 30(1):112-116. doi: 10.1111/mve.12139.

29. Acosta ICL, Luz HR, Faccini-Martínez ÁA, Muñoz-Leal S, Cerutti Junior C, Labruna MB. First molecular detection of Rickettsia sp. Atlantic rainforest in Amblyomma ovale Ticks from Espírito Santo state, Brazil. Braz J Vet Parasitol. 2018 (ahead of print). doi: 10.1590/S1984-296120180017

30. Nieri-Bastos FA, Szabó MP, Pacheco RC, Soares JF, Soares HS, Moraes-Filho $\mathrm{J}$, et al. Comparative evaluation of infected and noninfected Amblyomma triste ticks with Rickettsia parkeri, the agent of an emerging rickettsiosis in the New World. Biomed Res Inter. 2013; 2013:402737. doi: 10.1155/2013/402737.

31. Luz HR, Faccini JLH, Mclntosh D. Molecular analyses reveal an abundant diversity of ticks and Rickettsial agents associated with wild birds in two regions of primary Brazilian Atlantic Rainforest. Ticks Tick Borne Dis. 2017 Jun; 8(4):657665. doi: 10.1016/j.ttbdis.2017.04.012

32. Sabatini GS, Pinter A, Nieri-Bastos FA, Marcili A, Labruna MB. Survey of ticks (Acari: Ixodidae) and their Rickettsia in an Atlantic rain forest reserve in the State of São Paulo, Brazil. J Med Entom. 2010 Sep; 47(5):913-916. PubMed PMID: 20939360.

33. Silveira I, Pacheco RC, Szabó MP, Ramos HG, Labruna MB. Rickettsia parkeri in Brazil. Emerg Infect Dis. 2007 Jul; 13(7):1111-1113. doi: 10.3201/ eid1307.061397. PubMed PMID: 18214195.

34. Barbieri AR, Filho JM, Nieri-Bastos FA, Souza JC Jr, Szabó MP, Labruna MB. Epidemiology of Rickettsia sp. strain Atlantic rainforest in a spotted feverendemic area of Southern Brazil. Ticks Tick Borne Dis. 2014 Oct; 5(6):848-853. doi: 10.1016/j.ttbdis.2014.07.010.

35. Vizzoni VF, Silva AB, Cardoso KM, Dos Santos FB, Stenzel B, Amorim M, et al. Genetic identification of Rickettsia sp. strain Atlantic rainforest in an endemic area of a mild spotted fever in Rio Grande do Sul State, Southern Brazil. Acta Trop. 2016 Oct; 162: 142-145. doi: 10.1016/j.actatropica.2016.06.018. PubMed PMID: 27338183.

36. Krawczak FS, Binder LC, Oliveira CS, Costa FB, Moraes J Filho, Martins TF, et al. Ecology of a tick-borne spotted fever in Southern Brazil. Exp Appl Acarol. 2016 Oct; 70(2): 219-229. doi: 10.1007/s10493-016-0070-1. PubMed PMID: 27392739.

37. Guglielmone AA, Robbins RG, Apanaskevich DA, Petney TN, Estrada-Peña A, Horak IG. The hard Ticks of the world (Acari: Ixodida: Ixodidae). New York: Springer; 2014. 470p.

38. Szabó MP, Labruna MB, Garcia MV, Pinter A, Castagnolli KC, Pachecho RC, et al. Ecological aspects of the free-living Ticks (Acari: Ixodidae) on animals trails within Atlantic rainforest in South-eastern Brazil. Ann Trop Med Parasitol.
2009 Jan; 103(1): 57-72. doi: 10.1179/136485909X384956. PubMed PMID: 19173777.

39. Guglielmone AA, Beati L, Barros-Battesti DM, Labruna MB, Nava S, Venzal JM, et al. Ticks (Ixodidade) on humans in South America. Exp Appl Acarol. 2006; 40(2):83-100. PubMed PMID: 17103085.

40. Szabó MP, Labruna MB, Castagnolli KC, Garcia MV, Pinter A, Veronez VA, et al. Ticks (Acari: Ixodidae) parasitizing humans in an Atlantic rainforest reserve of Southeastern Brazil with notes on host suitability. Exp Appl Acarol. 2006; 39(34):339-346. PubMed PMID: 16900313.

41. Pereira MC, Szabó MP, Bechara GH, Matushima ER, Duarte JM, Rechav Y, et al. Ticks (Acari: Ixodidade) associated with wild animals in the Pantanal region of Brazil. J Med Entomol. 2000; 37(6):979-983. PubMed PMID: 11126563.

42. Labruna MB, Camargo LMA, Terrassini FA, Ferreira F, Schumaker TTS, Camargo EP. Ticks (Acari: Ixodidae) from the state of Rondônia, western Amazon, Brazil. Syst Appl Acarol, 2005; 10(1): 17-32. doi: https://doi.org/10.11158/saa.10.1.5.

43. Szabó MP, Olegário MM, Santos AL. Tick fauna from two locations in the Brazilian savannah. Exp Appl Acarol. 2007; 43(1):73-84. PubMed PMID: 17828441.

44. Luz HR, McIntosh D, Furusawa GP, Flausino W, Rozental T, Lemos ER, et al. Infection of Amblyomma ovale with Rickettsia species Atlantic rainforest in Serra do Mar, Sao Paulo State, Brazil. Ticks Tick Borne Dis. 2016; 7(6): 12651267. doi: 10.1016/j.ttbdis.2016.07.003. PubMed PMID: 27430967.

45. Barros-Battesti DMB, Arzua M, Bechara GH. Carrapatos de importância medico-veterinária da Região Neotropical: Um guia ilustrado para identificação de espécies. São Paulo: Vox/ICTTD-3; 2006. 223p.

46. Labruna MB, Jorge RS, Sana DA, Jácomo AT, Kashivakura CK, Furtado MM, et al. Ticks (Acari:Ixodida) on wild carnivores in Brazil. Exp Appl Acarol. 2005; 36(12): 149-163. PubMed PMID: 16082932.

47. Biggs HM, Behravesh CB, Bradley KK, Dahlgren FS, Drexler NA, Dumler JS, et al. Diagnosis and management of Tickborne Rickettsial diseases: Rocky mountain spotted fever and other spotted fever group rickettsioses, Ehrlichioses, and Anaplasmosis - United States. MMWR Recomm Rep. 2016 May; 65(3):1-44. doi: 10.15585/mmwr.rr6502a1.

48. Portillo A, García-García C, Sanz MM, Santibáñez S, Venzal JM, Oteo JA. A confirmed case of Rickettsia parkeri infection in a traveler from Uruguay. Am J Trop Med Hyg. 2013 Dec; 89(6):1203-1205. doi: 10.4269/ajtmh.13-0436.

49. Faccini-Martínez ÁA, Félix ML, Armua-Fernandez MT, Venzal JM. An autochthonous confirmed case of Rickettsia parkeri rickettsiosis in Uruguay. Ticks Tick Borne Dis. 2018 Mar; 9(3):718-719. doi: 10.1016/j.ttbdis.2018.02.015.

50. Medeiros AP, Souza AP, Moura AB, Lavina MS, Bellato V, Sartor AA, et al. Spotted fever group Rickettsia infecting ticks (Acari: Ixodidae) in the state of Santa Catarina, Brazil. Mem Inst Oswaldo Cruz. 2011 Dec; 106(8): 926-930. PubMed PMID: 22241112

51. Bechah Y, Socolovschi C, Raoult D. Identification of Rickettsial infection by using cutaneous swab specimens and PCR. Emerg Infect Dis. 2011 Jan; 17(1): 83-86. doi: 10.3201/eid1701.100854.

52. Socolovschi $C$, Renvoisé $A$, Brouqui $P$, Parola $P$, Raoult $D$. The use of eschar swabs for the diagnosis of African tick-bite fever. Ticks Tick Borne Dis. 2012 Dec; 3(5-6): 361-363. doi:10.1016/j.ttbdis.2012.10.018.

53. Portillo A, de Sousa R, Santibáñez S, Duarte A, Edouard S, Fonseca IP, et al. Guidelines for the detection of Rickettsia spp. Vector Borne Zoonotic Dis. 2017 Jan; 17(1):23-32. doi: 10.1089/vbz.2016.1966.

54. Ministério da Saúde (BR). Secretaria de Vigilância. Febre maculosa brasileira e outras riquetsioses. Guia de Vigilância em Saúde [Internet]. Brasília: Ministério da Saúde; 2017 [acesso 2017 Dez 29]. 425p. Disponível em: 
http://portalarquivos2.saude.gov.br/images/PDF/2017/outubro/16/VolumeUnico-2017.pdf.

55. Ramos RADN, Galindo MKF, Santana MDA, Faustino MADG, Alves LC. Parasitismo em humano por Amblyomma sp (Acari: Ixodidae), na cidade de Recife, estado de Pernambuco. Rev Soc Bras Med Trop. 2010 Oct; 43(5): 594595. doi: http://dx.doi.org/10.1590/S0037-86822010000500026.

56. Reck J, Marks FS, Guimaraes JA, Termignoni C, Martins JR. Epidemiology of Ornithodoros brasiliensis (mouro tick) in the Southern Brazilian highlands and the description of human and animal retrospective cases of tick parasitism. Ticks Tick Borne Dis. 2013 Fev; 4(1-2): 101-109. doi: 10.1016/j.ttbdis.2012.09.004. PubMed PMID: 23238249.
57. McGinley-Smith DE, Tsao SS. Dermatoses from ticks. J Am Acad Dermatol. 2003; 49(3): 363-392. PubMed PMID: 12963900.

58. Blanton LS. Rickettsiales: treatment and management of human disease. In: Thomas S, editor. Rickettsiales: Biology, molecular biology, epidemiology, and vaccine development. Berlin: Springer International Publishing; 2016. p.109124.

59. Oliveira SVD, Pereira SVC, Silva PMRB, Pereira JM, Gomes V, Amorim M, Gazeta GS, e Caldas EPD. Vigilância de ambientes da febre maculosa brasileira e outras riquetsioses: a etapa inicial de uma proposta para a formação de rede. Rev Pan Amaz Saud. 2015 Set; 6(3): 67-71. doi: http://dx.doi.org/10.5123/ S2176-62232015000300009.

\section{Como citar este artigo/How to cite this article:}

Faccini-Martínez AA, Oliveira SV, Cerutti C Junior, Labruna MB. Febre Maculosa por Rickettsia parkeri no Brasil: condutas de vigilância epidemiológica, diagnóstico e tratamento . J Health Biol Sci. 2018 Jul-Set; 6(3):299-312. 